\title{
Penentuan Suhu Nol Mutlak melalui Praktikum Termodinamika menggunakan Hukum Charles
}

\author{
Defrianto Pratama $^{1}{ }^{\text {, }}$, Ratu Fenny Muldiani ${ }^{1}$, Kunlestiowati Hadiningrum ${ }^{1}$ \\ ${ }^{1}$ Politeknik Negeri Bandung, Jl. Gegeralolong Hilir. Ds.Ciwaruga Bandung, Indonesia, \\ 40012 \\ * Penulis Penanggungjawab.E-mail: defrianto.pratama@polban.ac.id
}

\begin{abstract}
ABSTRAK
Konsep Termodinamika menjadi salah satu konsep dasar yang harus dikuasai oleh mahasiswa Politeknik Negeri Bandung untuk memahami prinsip kerja alat-alat rekayasa industri. Pemahaman konsep Termodinamika mahasiswa dapat dibangun melalui kegiatam praktikum, maka pada penelitian ini dilakukan perancangan dan optimasi peralatan praktikum Hukum Charles. Praktikum Hukum Charles dirancang untuk mendapatkan nilai suhu nol mutlak yang menjadi konstanta fundamental di Termodinamika. Hukum Charles menyatakan bahwa pada tekanan tetap dan ruang tertutup, volume gas ideal berbanding lurus terhadap suhu mutlaknya. Hasil pengujian rancangan alat praktikum hukum Charles menunjukkan bahwa grafik volume terhadap suhu memiliki nilai koefisien determinasi rata-rata $\left(\mathrm{R}^{2}\right)=0,9986$, hal ini menunjukkan bahwa volume dan suhu memiliki hubungan linier yang tinggi. Nilai suhu nol mutlak terbaik diperoleh sebesar $-273,45{ }^{\circ} \mathrm{C}$, sedangkan nilai suhu nol mutlak rata-rata diperoleh sebesar $-275,90{ }^{\circ} \mathrm{C}$ dengan ketidakpastian relatif kurang dari $2 \%$.
\end{abstract}

Kata Kunci : Termodinamika; Hukum Charles; Suhu Nol Mutlak 


\begin{abstract}
Thermodynamics is one of the basic concepts that must be mastered by engineering students at Politeknik Negeri Bandung, because it's used to recognize how industrial engineering tools work. Laboratory activities can help students to understand a difficult thermodynamic concept. The purpose of this study was to design and optimize a Charles's Law experiment device. Charles's Law experiment was designed to determine absolute zero temperature as a fundamental constant in thermodynamics. The experiment results show average of determination coefficient $(\mathrm{R} 2)=0,9986$ on the V-T graph, it's shows that the volume and temperature have a high linear relationship. The best absolute zero temperature was obtained at $-273,45^{\circ} \mathrm{C}$, while the average absolute zero temperature was obtained at $-275,90^{\circ} \mathrm{C}$ with relative error of less than $2 \%$.
\end{abstract}

Keywords: Thermodynamics; Charles's Law; Absolute Zero Temperature

\section{Pendahuluan}

Fisika Terapan merupakan mata kuliah dasar sebagai pendukung mata kuliah lanjut untuk setiap jurusan ilmu rekayasa di Politeknik Negeri Bandung (Polban). Mata kuliah Fisika Terapan sangat penting dalam membangun konsep dasar fisika untuk diterapkan mahasiswa pada ilmu rekayasa yang akan dipelajari di jurusan. Salah satu topik pada mata kuliah Fisika Terapan adalah konsep termodinamika. Penerapan konsep termodinamika banyak ditemukan pada prinsip kerja peralatan teknik di dunia industri, sehingga konsep termodinamika penting untuk dikuasai mahasiswa jurusan ilmu rekaysa Polban.
Selain pada perkuliahan kelas teori, konsep termodinamika juga perlu dipelajari melalui kegiatan praktikum di laboratorium untuk memperkuat penguasaan konsep mahasiswa. Kegiatan praktikum dalam pembelajaran sains (fisika) dapat membangun pemahaman konsep, pembuktian kebenaran konsep, meningkatkan keterampilan proses sains dan menumbuhkan minat terhadap pelajaran sains [1]. Untuk itu, diadakan kegiatan praktikum Fisika Terapan di Laboratorium Fisika Terapan Polban yang bertujuan untuk meningkatkan penguasaan konsep fisika mahasiswa melalui keterampilan proses sains. Pengembangan alat dan rancangan 
praktikum, terutama variasi jenis praktikum konsep termodinamika diperlukan untuk meningkatkatkan kualitas kegiatan praktikum di Laboratorium Fisika Terapan Polban.

Konsep suhu nol mutlak sangat penting dalam termodinamika dan merupakan konstanta fundamental fisika. Suhu nol mutlak adalah suhu terendah yang mungkin terjadi pada sebuah benda yaitu secara teori sebesar $-273.15^{\circ} \mathrm{C} \quad\left(\begin{array}{ll}0 & \mathrm{~K}\end{array}\right)$ [2]. Secara teori ketika sebuah molekul mencapai suhu nol mutlak, molekul tersebut tidak bergerak relatif terhadap seluruh molekul lain. Pada suhu nol mutlak molekul memiliki tingkat energi minimal. Konsep suhu nol mutlak diperlukan dalam memahami Hukum Termodinamika III, proses Ireversibel dan efesiensi mesin kalor [3].

Pada tahun 2015 peneliti dari MIT (Massachusetts Institute of Technology) dapat menentukan suhu nol mutlak dengan mendinginkan molekul hingga $500 \quad \mathrm{nK} \quad(500$ nanokelvin) [4], tetapi dengan peralatan yang mahal dan tidak mungkin dilakukan di laboratorium level fisika dasar.

Praktikum secara sederhana untuk menentukan suhu nol mutlak dapat menggunakan hukum Charles [5,6]. Perilaku gas ideal pada tekanan gas pada tekanan gas tetap memenuhi hukum Charles. Hukum Charles menyatakan bahwa jika gas dalam wadah tertutup volumenya dijaga konstan maka tekanan gas ideal berbanding lurus dengan temperatur mutlaknya [7]. Secara matematis hukum Charles dituliskan sebagai berikut,

$$
\frac{V}{T}=\frac{n R}{p}=C
$$

Dimana $\mathrm{V}$ adalah volume gas $\left(\mathrm{m}^{3}\right), \mathrm{T}$ adalah suhu gas (K), n adalah jumlah mol gas (mol) bernilai tetap, $\mathrm{P}$ adalah tekanan gas $(\mathrm{Pa})$ bernilai tetap dan $\mathrm{R}$ $(8,314 \mathrm{~J} / \mathrm{mol} \mathrm{K})$ adalah ketetapan gas ideal.

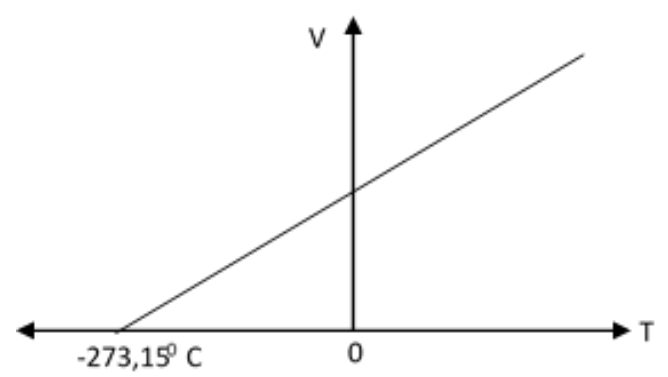

Gambar 1. Grafik V-T hukum Charles.

Pada gambar 1, grafik V-T menuju suhu rendah akan selalu memotong sumbu $\mathrm{T}$ disekitar $-273,15^{\circ} \mathrm{C}$. Sehingga dapat disimpulkan ketika suhu gas didinginkan mendekati suhu nol mutlak, volumenya mendekati nol. 


\section{Bahan dan Metode}

Penelitian ini dilaksanakan di Laboratorium Fisika Terapan Politeknik Negeri Bandung melalui dua tahapan.

Tahapan pertama adalah merancang alat praktikum hukum Charles. Praktikum hukum Charles meggunakan alat-alat pada tabel 1 .

Tabel 1. Alat-alat praktikum hukum Charles

\begin{tabular}{llc}
\hline No & \multicolumn{1}{c}{ Nama Alat } & Jumlah \\
\hline 1 & Termometer gas, panjang 35 & 1 \\
\hline 2 & Pompa vacum & 1 \\
\hline 3 & Tabung reaksi panjang & 1 \\
\hline 4 & Stand base, V saped 20 cm & 1 \\
\hline 5 & Stand rod, 47 cm & 1 \\
\hline 6 & Clamp with jaw clamp & 2 \\
\hline 7 & Hot plate & 1 \\
\hline 8 & Gelas ukur, 400 ml & 1 \\
\hline 9 & Termometer digital & 1 \\
\hline
\end{tabular}

Pada termometer gas terdapat udara yang terjebak dibawah tetesan raksa. Tetesan raksa sebagai indikator perubahan volume akibat perubahan suhu. Volume udara yang terjebak dapat diatur dengan menggunakan pompa vakum. Air sebanyak $400 \mathrm{ml}$ dipanaskan hingga suhu sekitar $70^{\circ} \mathrm{C}$, kemudian air tersebut dituangkan kedalam tabung reaksi panjang. Termometer gas dimasukan kedalam air panas tersebut, tunggu hingga tetesan raksa berhenti naik, kemudian amati penurunan tinggi raksa akibat proses pendinginan suhu air. Catat perubahan ketinggian air raksa terhadap perubahan suhu air.

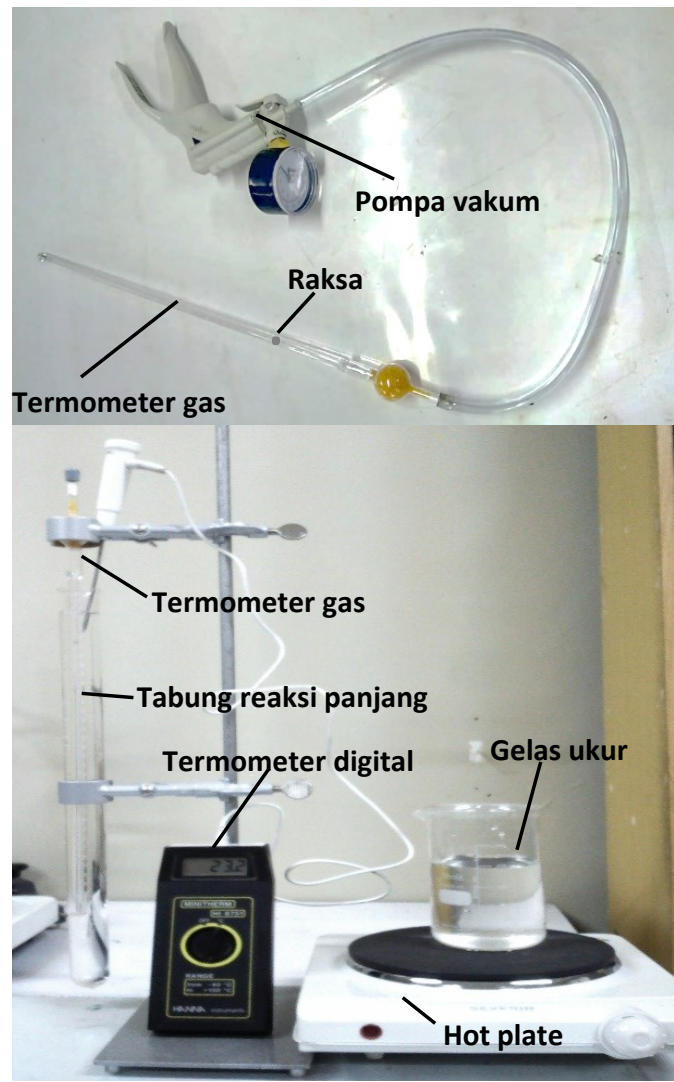

Gambar 2. Rancangan alat praktikum hukum Charles

Tahap kedua adalah melakukan pengujian alat praktikum percobaan hukum Charles. Pengujian dilakukan berulang untuk mendapatkan data terbaik dan mengurangi ketidakpastian hasil pengukuran. Data hasil pengukuran tersebut diolah menggunakan Metode Kuadrat Terkecil/Regresi Linier untuk mendapatkanan nilai suhu nol mutlak. 


\section{Hasil dan Pembahasan}

Praktikum hukum Charles dilakukan pada suhu udara luar $24,8^{0} \mathrm{C}$, tekanan udara luar 924 mbar, dan kelembaban udara luar $77 \%$.

Pengambilan data diulangi sebanyak lima kali. Data pengukuran kemudian diplot pada grafik dengan volume (sumbu y) sebagai fungsi suhu (sumbu $\mathrm{x}$ ). Hasil pengukuran dapat dilihat pada gambar 3 .

Pada gambar 4 data hasil pengukuran didekati dengan garis linier menggunakan Metode Kuadrat Terkecil, kemudian garis tersebut di ektrapolasi menuju suhu negatif hingga memotong di titik $\mathrm{V}=0$ (intersection point). Titik potong tersebut merupakan nilai suhu nol mutlak hasil praktikum. Nilai suhu nol mutlak hasil praktikum akan dibandingkan dengan nilai suhu mutak berdasarkan teori.

Data praktikum hukum Charles yang diplotkan dalam grafik menunjukkan nilai koefisien determinasi rata-rata $\left(\mathrm{R}^{2}\right)=$ 0,9986. Hal ini menunjukkan bahwa volume dan suhu memiliki hubungan linier yang tinggi, serta kuatnya pengaruh suhu terhadap perubahan volume pada tekanan tetap.
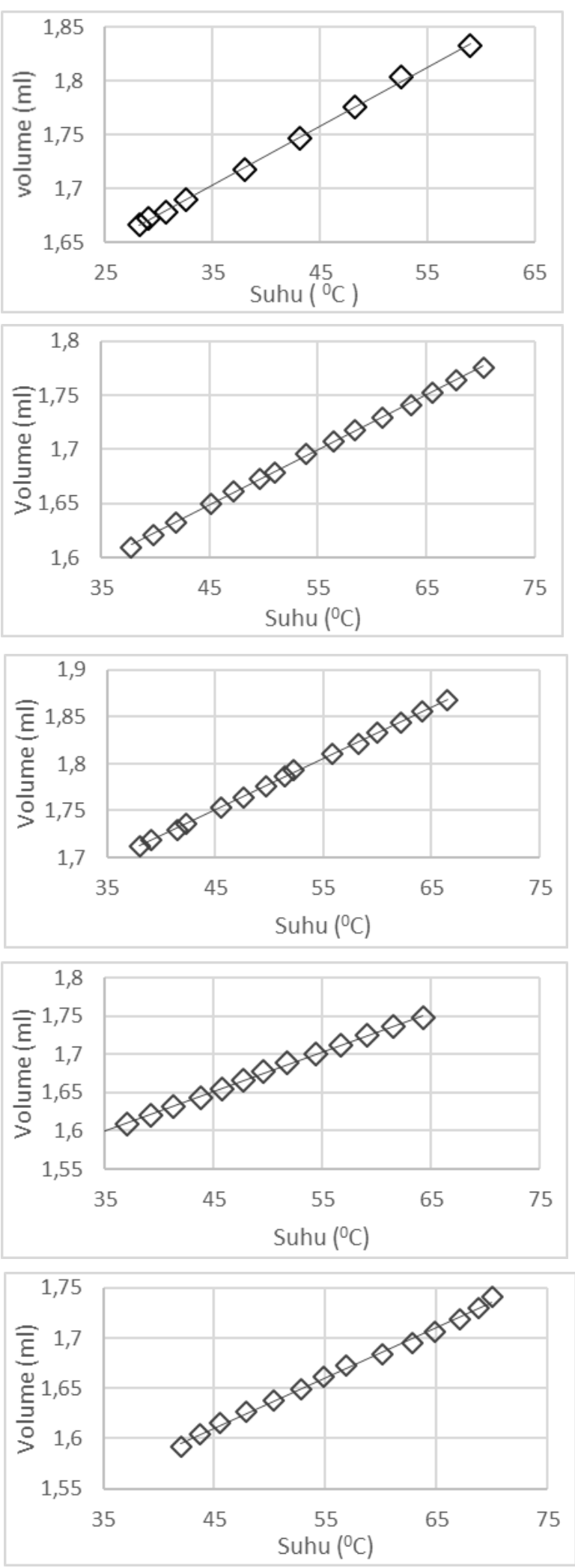

Gambar 3. Grafik volume terhadap suhu data praktikum hukum Charles 

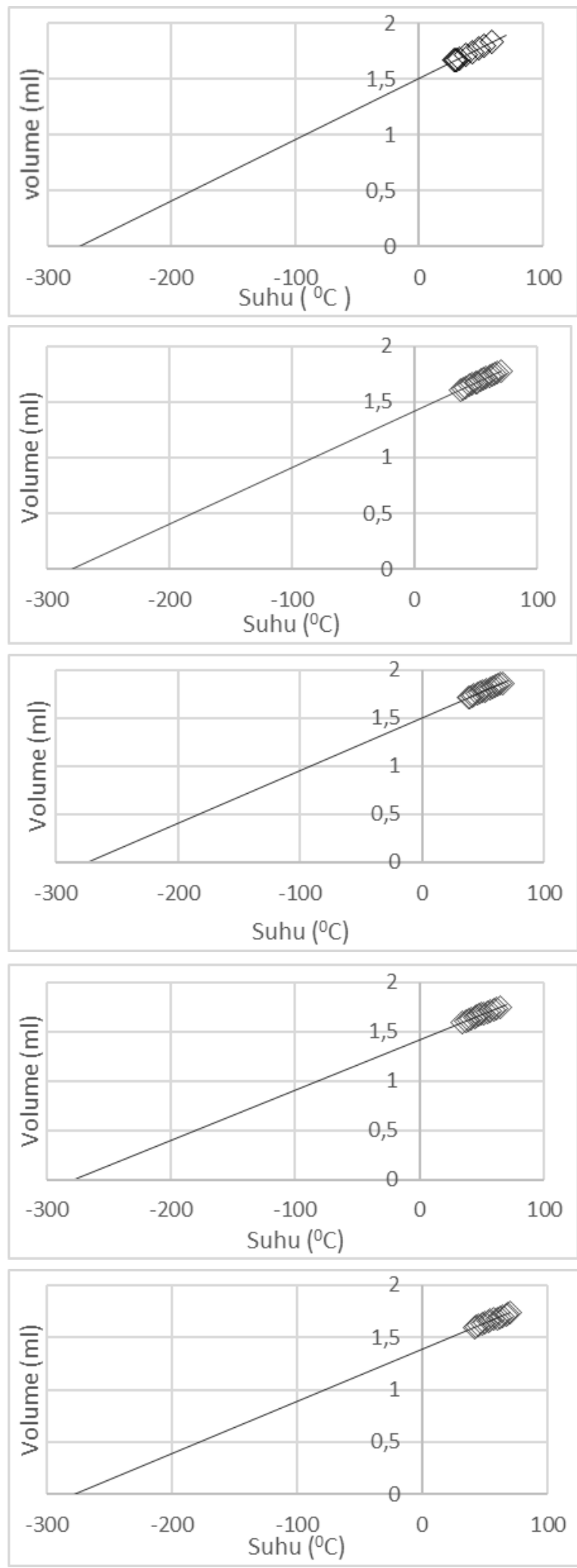

Gambar 4. Ektrapolasi Grafik volume terhadap suhu menggunakan metode regresi linier
Suhu nol mutlak didapat dengan mengunakan metode kuadrat terkecil/ regresi linier dari grafik volume terhadap suhu. Suhu nol mutlak praktikum dapat dihitung ketidakpastian relatif nya dengan perumusan sebagai berikut:

$$
K S R=\left|\frac{T_{0 \text { mutlak prak }}-T_{0 \text { mutlak teori }}}{T_{\mathrm{n} \text { mutlak teari }}}\right| \times 100 \% \text { (2) }
$$

Hasil pengolahan data dapat dilihat pada tabel 2.

Tabel 2. Hasil praktikum hukum Charles

\begin{tabular}{lll}
\hline Perc.ke- & $\begin{array}{l}\text { Suhu nilai Mut- } \\
\text { lak } \\
\end{array}$ & $\begin{array}{l}\text { KSR } \\
\left({ }^{0} \mathrm{C}\right)\end{array}$ \\
\hline 1 & $-274,54$ & 0,5 \\
\hline 2 & $-278,35$ & 1,9 \\
\hline 3 & $-273,45$ & 0,1 \\
\hline 4 & $-275,80$ & 1,0 \\
\hline 5 & $-277,16$ & 1,5 \\
\hline
\end{tabular}

Nilai suhu nol mutlak terbaik diperoleh sebesar $-273,45^{\circ} \mathrm{C}$, dari lima kali pengulangan praktikum dengan perbedaan $0,1 \%$ dibandingkan dengan suhu nol mutlak teori. Sedangkan secara keseluruhan, rata-rata nilai suhu nol mutlak sebesar $-275,90{ }^{\circ} \mathrm{C}$.

Ketidakpastian relatif suhu nol mutlak praktikum menunjukan nilai relatif kecil yaitu dibawah $2 \%$ jika dibandingkan dengan nilai suhu nol mutlak secara teori. Salah satu faktor yang menyebabkan perbedaan adalah pengukuran suhu tidak diukur langsung di dalam udara yang terjebak di termometer gas sehingga 
penurunan suhu yang terukur di air tidak tepat sama dengan penurunan suhu udara terjebak pada termometer gas.

\section{Simpulan}

Penentuan nilai suhu nol mutlak melalui praktikum hukum Charles menunjukan hasil yang cukup baik dengan perbedaan dibawah $2 \%$ dibandingkan dengan suhu nol mutlak secara teori, sehingga praktikum ini sangat mungkin dilakukan untuk perkuliahan Fisika Terapan di Politeknik Negeri Bandung. Akan tetapi, perlu dilakukan percobaan lanjutan untuk mengetahui pengaruh kondisi awal yaitu; suhu pemanasan air dan volume awal udara yang terjebak di termometer gas, untuk mendapatkan hasil terbaik.

\section{Referensi}

1. Koretsky, M.D, Christine, K., \& Gummer. (2011). Learning in the Laboratory: Comparison of Industrially Situated Virtual Laboratories to Capstone Physical Laboratories. Journal of Engineering Education. 100 (3) : 540-573.

2. Bureau International des Poids et Mesures. (2006). The International System Unit 8th edition. Organisation Intergouvernementale de la Convention du Mètre.
3. Halliday, Resnick, \& Walker. (2011). Fundamentals of Physics 9th Edition. John Wiley \& Sons, Inc.

4. Chu, J. (10 Juni 2015). MIT team creates ultracold molecules at near absolute zero, molecules may start to exhibit exotic states of matter. URL https://news.mit.edu/2015/ultracoldmolecules-0610.

5. Kim, M.H., et.al. (2001). A Simple Laboratory Experiment for Determination of Absolute Zero. Journal of Chemical Education.78 (2) : 238-240.

6. Ivanov, D.T. (2003). Experimental Determination of Absolute Zero Temperature. The Physiccs Teacher. $41: 173-175$.

7. Giancoli, C.G. (2016). Physics: Principles with Applications, Global Edition. Pearson Education Limited. 